\title{
THE DROPLET SIZE AND PENETRATION HEIGHT OF A KEROSENE JET IN A CROSSFLOW
}

\author{
Xianggeng Wei, ${ }^{1, *}$ Lingyu Li, ${ }^{1}$ Zhixin Zhao, ${ }^{1}$ Tao Bo, ${ }^{2}$ \\ Xianggang Bian, ${ }^{1}$ E Youxing Zuo ${ }^{1}$
}
${ }^{1}$ Science and Technology on Combustion, Internal Flow and Thermo-Structure Laboratory, Northwestern Polytechnical University, Xi'an 710072, China
${ }^{2} X i^{\prime}$ an Aerospace Information Research Institute, Xi'an 710072, China
*Address all correspondence to: Xianggeng Wei, Science and Technology on Combustion, Internal Flow and Thermo-Structure Laboratory, Northwestern Polytechnical University, Xi'an 710072, China; Tel.: 135-72495641, Fax: 029-88493406,
E-mail: realysnow@nwpu.edu.cn

Original Manuscript Submitted: 4/5/2020; Final Draft Received: 8/30/2020

\begin{abstract}
The atomization and mixing processes of fuel in crossflows are among the important aspects of research into rocket-based combined-cycle (RBCC) engine technology. In this paper, the droplet size and penetration height of the kerosene jet in crossflows are studied. The influences of the orifice diameter, number, and arrangement, the injection pressure drop of fuel, the orifice diameter and the Mach number of the crossflow are analyzed applying different optical measuring methods. The results reveal that the injection pressure drop of fuel and the crossflow Mach number are both positively correlated with the atomization performance, whereas the orifice diameter is negatively correlated with the atomization performance. By analyzing the penetration height under different operating conditions, it can be seen that when the other factors are kept constant, the penetration height increases with increasing orifice diameter and pressure drop. Using a least-squares, an empirical formula for the jet penetration height in terms of momentum flux ratio and axial distance was obtained.
\end{abstract}

KEY WORDS: crossflow, transverse jet, droplet size, penetration height, RBCC

\section{INTRODUCTION}

The rocket-based combined cycle (RBCC) engine organically combines the advantages of high thrust-to-weight ratio of the rocket engine and high specific impulse of the ramjet. It can work in a wide range of crossflow Mach number, and it is one of the important propulsion forms of reusable spacecraft and hypersonic aircraft. In the engine, the residence time of the crossflow in the combustion chamber is very short, usually on the order of milliseconds. During this time, the liquid fuel needs to complete the processes of atomization, mixing, and combustion, each of which directly affects engine performance. The atomization and mixing of fuel in the engine are generally very complex. In the engine, the crossflow enters the combustion chamber from the inlet and moves toward the outlet. The fuel jet is injected into the combustion chamber in a perpendicular direction to the crossflow and mixes with it (Ebrahimi, 2013). In the complete process, with the influences of the shock wave and various vortexes, there are a large number of droplets breaking down, coalescing, and evaporating. The interaction between the gas and 


\begin{tabular}{|c|c|c|c|}
\hline \multicolumn{4}{|c|}{ NOMENCLATURE } \\
\hline $\begin{array}{l}a, b, c \\
d \\
h \\
q \\
P \\
P_{0} \\
\Delta P \\
v_{l}, v_{g}\end{array}$ & $\begin{array}{l}\text { constants } \\
\text { orifice diameter, } \mathrm{mm} \\
\text { penetration height, } \mathrm{mm} \\
\text { momentum flux ratio } \\
\text { static pressure, } \mathrm{MPa} \\
\text { total pressure, } \mathrm{MPa} \\
\text { injection pressure drop, } \mathrm{MPa} \\
\text { velocity of kerosene } \\
\text { and crossflow, } \mathrm{m} / \mathrm{s}\end{array}$ & $\begin{array}{l}x \\
\mathrm{~T} \\
\mathrm{Ma} \\
\text { SMD } \\
\Delta S\end{array}$ & $\begin{array}{l}\text { the density } \\
\text { of kerosene } \\
\text { and crossflow, } \mathrm{g} / \mathrm{cm}^{3} \\
\text { axial distance, } \mathrm{mm} \\
\text { temperature, } \mathrm{K} \\
\text { Mach number } \\
\text { Sauter mean } \\
\text { diameter, } \mu \mathrm{m} \\
\text { relative size range }\end{array}$ \\
\hline
\end{tabular}

liquid is complex and always changing, and the breakup process is highly nonlinear (Krishnan, 2013; Jinbum and Seungsoo, 2018). The atomization and mixing effects directly determine the combustion efficiency of the fuel (Wang et al., 2015a). Therefore, the study of the atomization and mixing mechanisms of fuel in crossflows is extremely important.

Since the 1960s, many scholars have studied the atomization characteristics and penetration height of fuel in crossflows in relation to engine performance (Allan and Joseph, 1971; Gad et al., 2018; Joshi and Schetz, 2015; Kolpin et al., 1968; Kush et al., 1973; Wang et al., 2014). In the early stages of this research, studies mainly focused on the influence of different factors, including the injection mode (Gad et al., 2018; Kolpin et al., 1968; Lin et al., 2004), the physical properties of the liquid (Allan and Joseph, 1971; Kush et al., 1973), and the shape of the jet hole (Joshi and Schetz, 2015; Kush et al., 1973), and a large quantity of droplet distribution data was obtained. The study of atomization characteristics in crossflows mainly focuses on the size and velocity of the droplets. Krishnan (2013) studied the mechanism of interaction of jets with crossflow, mainly analyzing jet behavior, jet trajectory, entrainment and mixing in crossflow. Miller (2006) studied atomization characteristics in a subsonic crossflow using digital holographic diagnosis technology and compared the size distribution of droplets at different gas-liquid ratios. Tambe et al. (2005) studied the influence of the liquid-gas momentum ratio, orifice diameter, crossflow velocity, and physical property parameters on the droplet size distribution in a subsonic crossflow using a phase Doppler particle analyzer (PDPA). Lin et al. (2004) studied the structures of water jets in a Mach 1.94 supersonic crossflow by using a PDPA. Their research revealed that when $x / d$ is 100 , the atomization process is basically complete, and the flux-averaged Sauter mean diameter (SMD) is on the order of $10 \mu \mathrm{m}$. The droplet size and velocity distribution are "S" shaped. The shadow method (Lin and Kennedy, 2000), schlieren method (Liu et al., 2008; Yu et al., 2004), PDPA (Lin and Kennedy, 2002), and high-speed photography (Yu et al., 2004) are mainly used to examine the penetration height. Morad and Khosrobeygi (2019) studied the trajectory and penetration height of elliptical liquid jets with different aspect ratios emerging into a low-speed crossflow of air. They propose an empirical correlation for the injector geometries and the range of momentum ratios, Weber numbers, and Reynolds numbers used in their study, and a theoretical model for the trajectory of the liquid column for an initially elliptical liquid emerging into a crossflow is presented. Wang et al. (2015a) studied the penetration height of kerosene in a crossflow using planar laser-induced fluorescence (PLIF) and analyzed the influence of the momentum ratio and Weber number on the penetration height. They found an empirical formula for the penetration height by fitting for the momentum ratio, Weber number, 
and axial distance. Liu et al. (2008) measured the spray penetration height using the schlieren method and fitted a corresponding empirical formula for the penetration height. They indicated that the momentum flux ratio and orifice diameter are the main factors affecting penetration. Sun et al. (2013) studied the coherent structure and penetration of transverse gas jets in supersonic turbulence using nanoparticle-based planar laser scattering (NPLS) technology and proposed an empirical formula for the penetration height. Stenzler et al. (2006) believe that at a low Weber number, momentum flux ratio, and liquid viscosity have a significant effect on penetration. They found that the penetration height decreased when the Weber number and liquid viscosity increased and that the increase in the momentum flux ratio can increase the penetration height. In terms of atomization effect on combustion process, National University of Defense Technology studied the effects of different injection positions of the jet on spark ignition and combustion stability by experiment (Wang et al., 2013, 2015b; Sun et al., 2012) and numerical simulation (Wang et al., 2015c), and proposed that the different injection positions will change the mixing and convection intensity of fuel and air. When the mixing is insufficient and the convection intensity is low, it may lead to ignition failure or bring great difficulty to stable combustion. Huang (2016) analyzed the main ways to improve the mixing and combustion efficiency in the scramjet engine, and proposed to improve the mixing and combustion efficiency by optimizing the multiport injection scheme.

There are many factors that influence the size of the spray. Researchers have mainly studied the orifice diameter, pressure drop, velocity of the crossflow, orifice arrangement, and physical parameters of the liquid. Due to different test methods and operating conditions, the results reveal some differences, but the overall trend is the same. As a result of different experimental environments and measurement methods, the formulas for penetration height obtained by different researchers can be different. By examining past research, it can be seen that there have been relatively few studies on the mechanisms of jet atomization, and they are not yet fully understood. This paper focuses on the droplet size and penetration height of kerosene in crossflows. The SMD and relative size range of the spray were measured by phase Doppler anemometry (PDA). The penetration height of atomized kerosene was measured using high-speed photography and the schlieren method, and an empirical formula for the penetration height was obtained by leastsquares. The atomization mechanism of kerosene was studied by analyzing the influence of the momentum flux ratio, orifice diameter, and injection pressure drop on the atomization process.

\section{EXPERIMENTAL SYSTEM AND OPERATING CONDITIONS}

\subsection{Experimental System}

In this experiment, the droplet sizes and penetration height of kerosene were studied. The system consists of a subsonic/supersonic flow system, an optical observation chamber, a kerosene supply system, and a test and control system, as presented in Fig. 1. The subsonic/supersonic flow system includes a high-pressure gas cylinder, an equipment throat, and a movable tail cone, etc. Air flows passes through the equipment throat and enters the optical observation chamber from its left side. Kerosene then is injected into the optical observation chamber from the bottom through a stop valve, a filter, an orifice plate, and an electromagnetic valve and is atomized and mixed with the crossflow. The pressure provided by the high-pressure gas cylinder is $4-6 \mathrm{MPa}$, and the adjustable range of the inlet flow is 0.5-2.5 MPa after passing through the rectifier and decompression device. The measurement method is non-contact optical measurement. PDA was used to measure the particle size and distribution of the spray, and high-speed photography and

Volume 30, Issue 7, 2020 


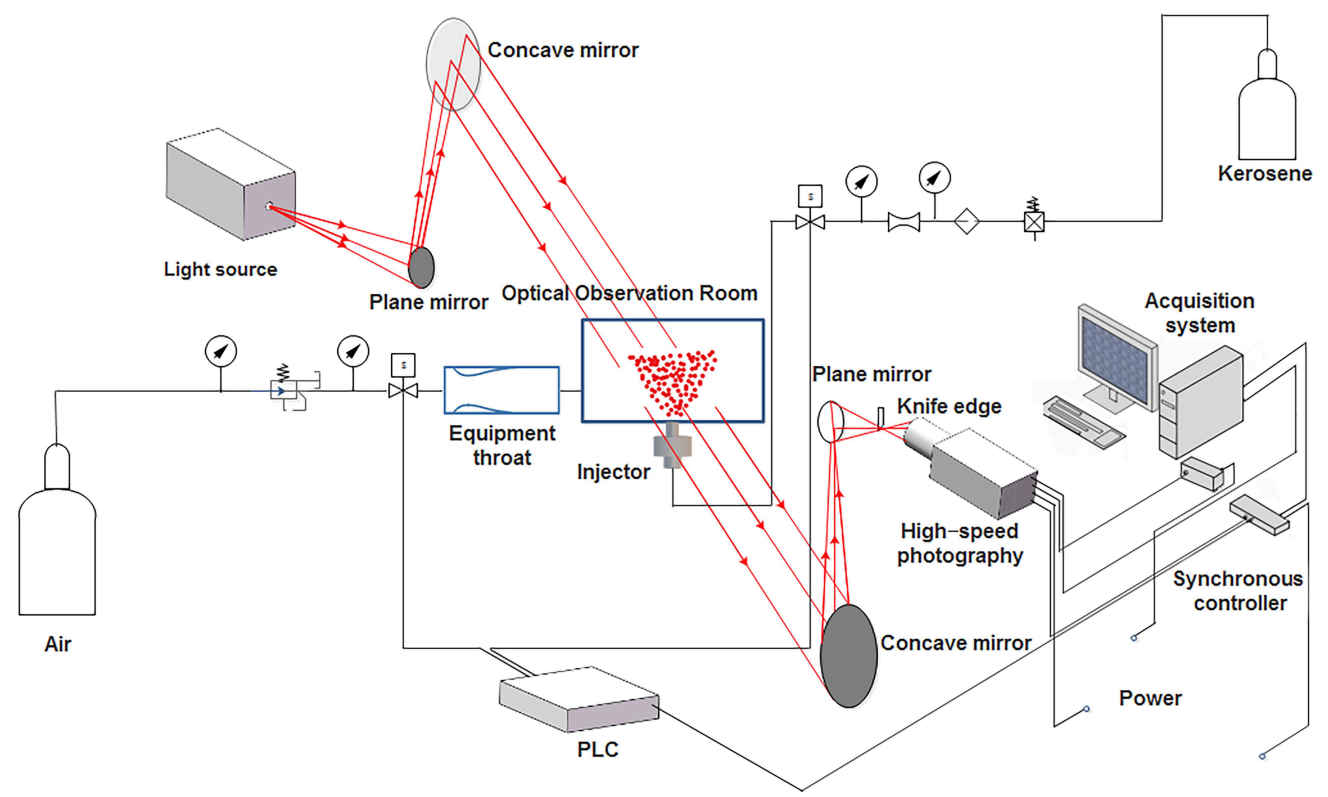

FIG. 1: Schlieren system in supersonic crossflows (the PDA test system and the high-speed photography system are similar to the schlieren test system and are not presented here)

the schlieren method were used to record the trajectory of atomized kerosene in the flow field. Figure 2 presents the specific structure of the chamber. The injection panel is located at the center of the bottom of the observation chamber. The optical observation chamber is a cuboid. Two quartz windows installed on front and rear sides of the test section provide visual observation and optimal instrumentation access. The length, width, and height of the observation chamber are $360 \mathrm{~mm}, 90 \mathrm{~mm}$, and $203 \mathrm{~mm}$. And the size of quartz window is $150 \mathrm{~mm} \times 230 \mathrm{~mm}$. A pressure-fed system was selected for the kerosene supply, which includes a fuel storage tank, a stop valve, a filter, a flowmeter, and an injector. The programmable logic controller is used in the system to precisely control the air inlet flow and liquid fuel injection system, heating system,

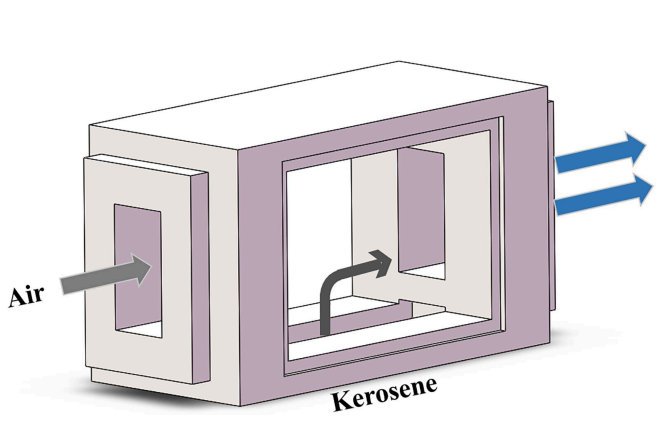

(a)

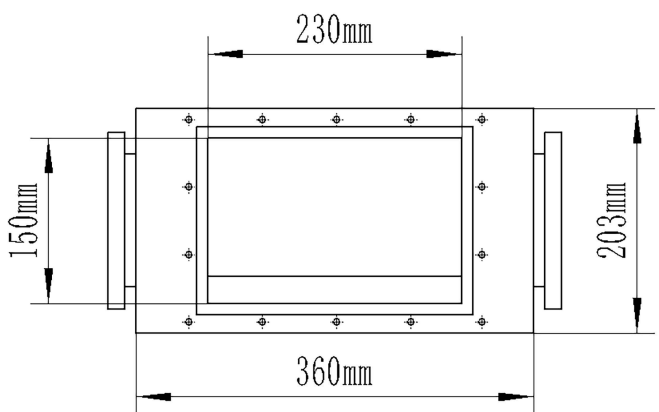

(b)

FIG. 2: Structure of the optical observation chamber: (a) three-dimensional section view of insulation spray structure; (b) design drawing of the optical observation chamber 
and blowing system. At the same time, the pressures of each transfer section, equipment throat, optical observation chamber, and supply system are collected in real time, thereby obtaining the pressure of the engine combustion chamber and upstream wall surface.

\subsection{Experimental Conditions}

The droplets size and penetration heights of kerosene jet flows were studied for various influencing factors, such as the number of orifices and their diameter, orifice arrangement, injection pressure drop, and crossflow Mach number. The study of droplet size mainly includes SMD and droplet size distribution. The SMD and the relative size ranges of the spray under different influencing factors were measured using PDA. For the penetration height, high-speed photography and the schlieren method were used to obtain the trajectory of the atomized kerosene, and the acquired images were processed to find an empirical formula for the penetration height. The influence of different factors on the atomization process was studied using a control-variable method. Different injection panels were designed for testing. Details of the injection panels are presented in Table 1. A subsonic crossflow was selected as the main state when setting the test conditions, and a small number of supersonic conditions were examined for comparison.

To make the experimental results more visible, a $0.7 \mathrm{~mm}$ aperture was chosen as the orifice diameter for multifactor comparison. The specific operating conditions are presented in Table 2 . The orifice arrangement is shown in Fig. 3.

TABLE 1: Injection panel information

\begin{tabular}{cccccc}
\hline Group & $\mathbf{1}$ & $\mathbf{2}$ & $\mathbf{3}$ & $\mathbf{4}^{\#}$ & $\mathbf{5}^{\# \#}$ \\
\hline Orifice diameter $/ \mathrm{mm}$ & 0.7 & 0.5 & 0.4 & 0.4 & 0.4 \\
Pore number & 1 & 1 & 1 & 3 & 3 \\
Mass flow rate $\left[\Delta P=1 \mathrm{MPa}\left(\mathrm{g} \cdot \mathrm{s}^{-1}\right)\right]$ & 12.3 & 6.28 & 4 & 12 & 12 \\
Mass flow rate $\left[\Delta P=2 \mathrm{MPa}\left(\mathrm{g} \cdot \mathrm{s}^{-1}\right)\right]$ & 17.4 & 8.88 & 5.68 & 17.1 & 17.1 \\
\hline
\end{tabular}

\#inear distribution.

\#\# Equilateral triangle distribution.

TABLE 2: Test setting

\begin{tabular}{cccc}
\hline Conditions & Injection panel & $\boldsymbol{\Delta} \boldsymbol{P}(\mathbf{M P a})$ & Inflow Mach number (Ma) \\
\hline SUB1-0.7 & 1 & 1 & 0.6 \\
SUB2-0.4 & 3 & 2 & 0.6 \\
SUB2-0.4L & 4 & 2 & 0.6 \\
SUB2-0.4S & 5 & 2 & 0.6 \\
SUB2-0.5 & 2 & 2 & 0.6 \\
SUB2-0.7 & 1 & 2 & 0.6 \\
SUP1-0.7 & 1 & 1 & 2 \\
SUP2-0.7 & 1 & 2 & 2 \\
\hline
\end{tabular}

SUB = subsonic, SUP = supersonic; " 1,2 " = pressure drop $(\mathrm{MPa}), " 0.4,0.5,0.7$ " = orifice diameter $(\mathrm{mm}), \mathrm{L}=$ orifices were distributed in a straight line, $\mathrm{S}=$ orifices in an equilateral triangle, and $\mathrm{X}=$ fuel injection preferred.

Volume 30, Issue 7, 2020 


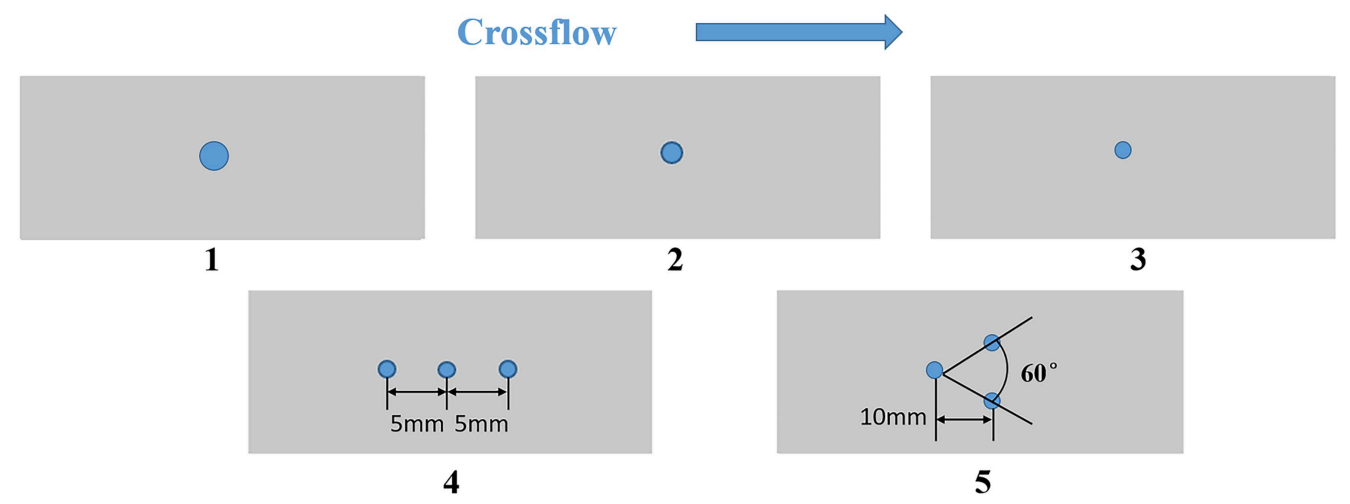

FIG. 3: Orifice arrangement

\section{RESULTS}

\subsection{Analyzing Atomization Characteristics}

This study used the SMD and relative size range $(\Delta S)$ to evaluate the atomization characteristics. The ambient temperature was $270 \mathrm{~K}$. The static temperature and Mach number were calculated according to the total pressure, static pressure, and total temperature, and the momentum flux ratio was calculated according to the injection pressure drop. The momentum flux ratio is the dynamic pressure ratio of the jet to the crossflow, the expression for which is presented in Eq. (1). The test results under different operating conditions are presented in Table 3, and the distribution of droplet size are shown in Fig. 4.

$$
q=\frac{1 / 2 \rho_{l} v_{l}^{2}}{1 / 2 \rho_{g} v_{g}^{2}}=\frac{2 \Delta P}{P \mathrm{Ma}^{2}}
$$

It can be seen from Eq. (1) that the momentum flux ratio is related to the total pressure, static pressure, and fuel injection pressure drop. The jet-to-crossflow momentum flux ratio can be controlled directly by controlling the fuel injection pressure drop. Analyzing the results, the Mach number of subsonic flow was about 0.6 , and the speed of supersonic flow was controlled by the equipment throat to be Mach 2 (the error range of Mach number is $0.5 \%$ ). The above

TABLE 3: Measurement results of droplet size

\begin{tabular}{ccccccc}
\hline Conditions & Injection panel & $\boldsymbol{\Delta} \boldsymbol{P}(\mathbf{M P a})$ & $\mathbf{M a}$ & $\boldsymbol{q}$ & $\boldsymbol{S M D}(\boldsymbol{\mu m})$ & $\boldsymbol{\Delta}_{\boldsymbol{s}}$ \\
\hline SUB1-0.7 & 1 & 1.02 & 0.65 & 8.62 & 37.09 & 2.24 \\
SUB2-0.4 & 3 & 2.03 & 0.5 & 16.74 & 18.93 & 1.23 \\
SUB2-0.4L & 4 & 1.73 & 0.63 & 11.32 & 14.87 & 0.77 \\
SUB2-0.4S & 5 & 1.68 & 0.63 & 12.09 & 14.55 & 1.19 \\
SUB2-0.5 & 2 & 1.9 & 0.57 & 14.09 & 18.18 & 1.14 \\
SUB2-0.7 & 1 & 1.83 & 0.64 & 14.18 & 13.17 & 0.89 \\
SUB2-0.7X & 1 & 1.86 & 0.67 & 18.02 & 12.88 & 1.3 \\
SUP1-0.7 & 1 & 1.05 & 2 & 0.55 & 30.89 & 1.84 \\
\hline
\end{tabular}




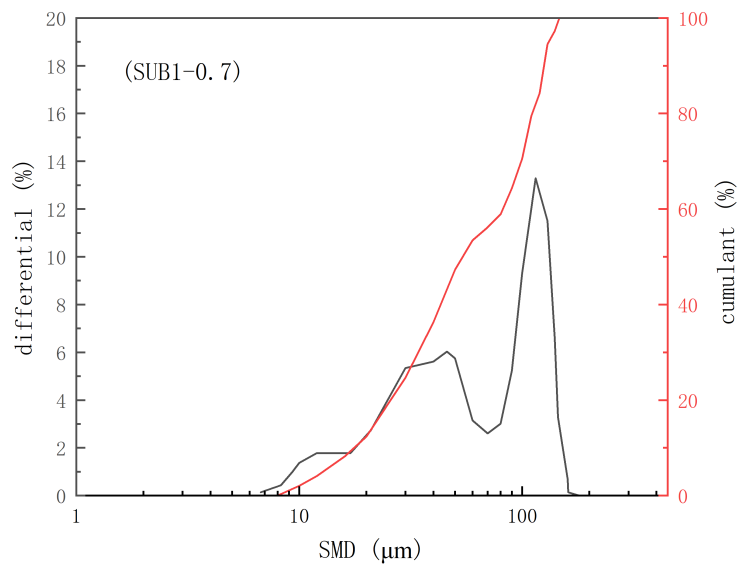

(a)

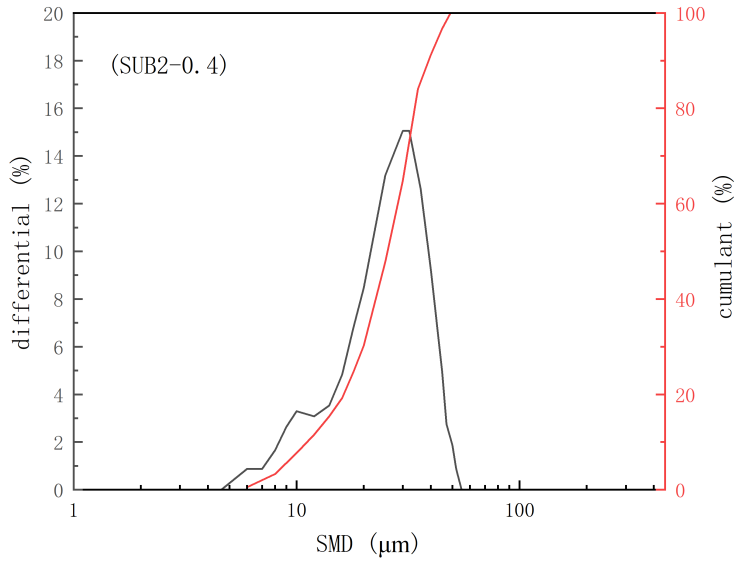

(b)

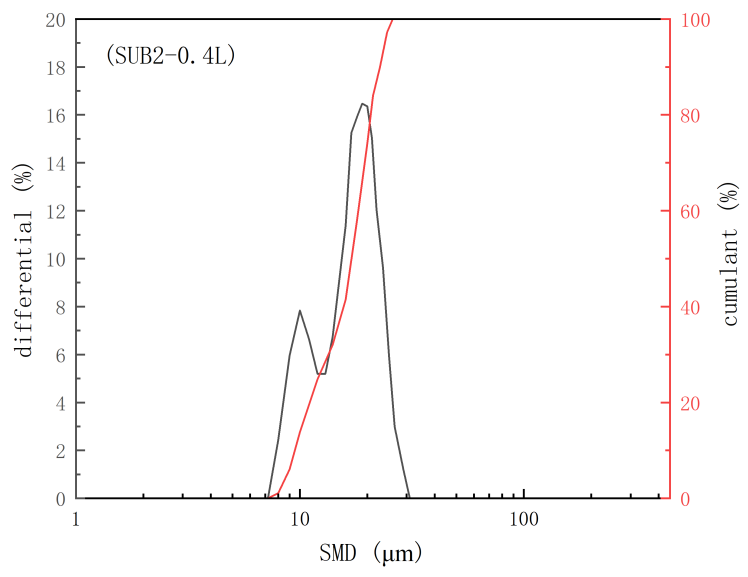

(c)

FIG. 4.

Volume 30, Issue 7, 2020 


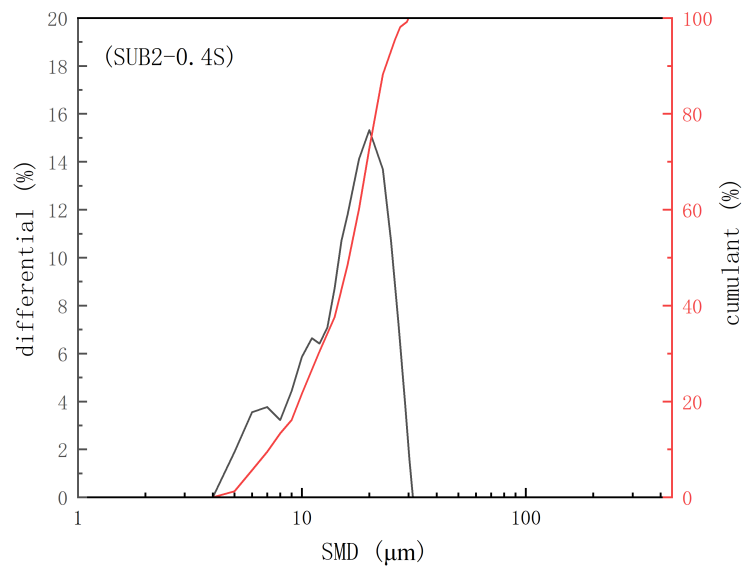

(d)

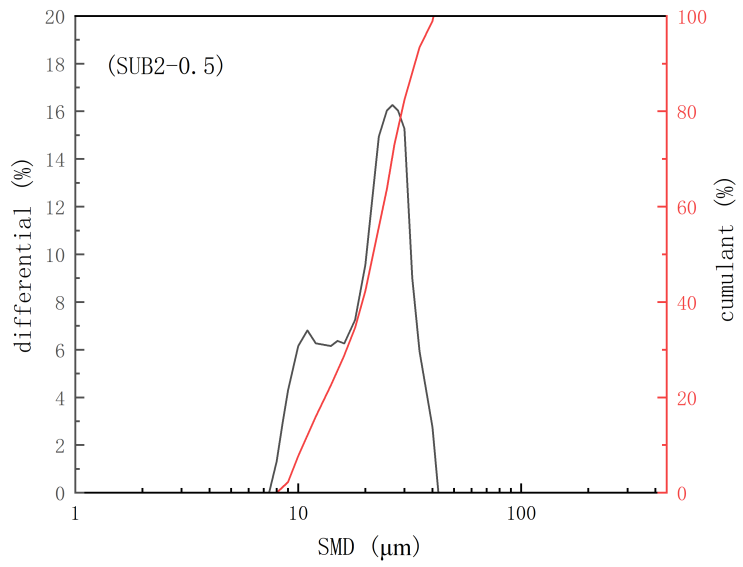

(e)

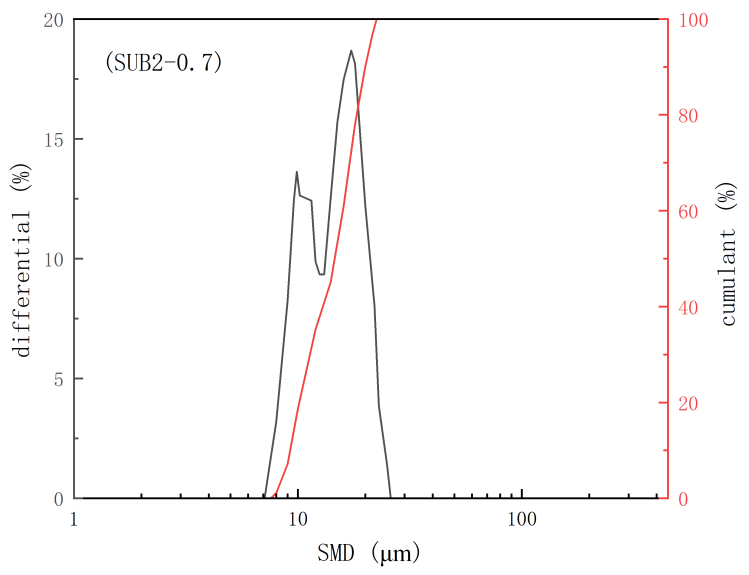

(f)

FIG. 4. 


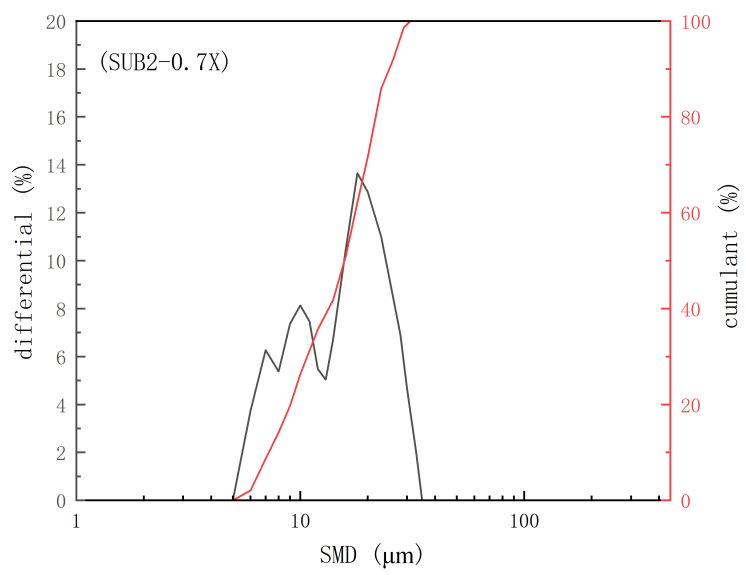

(g)

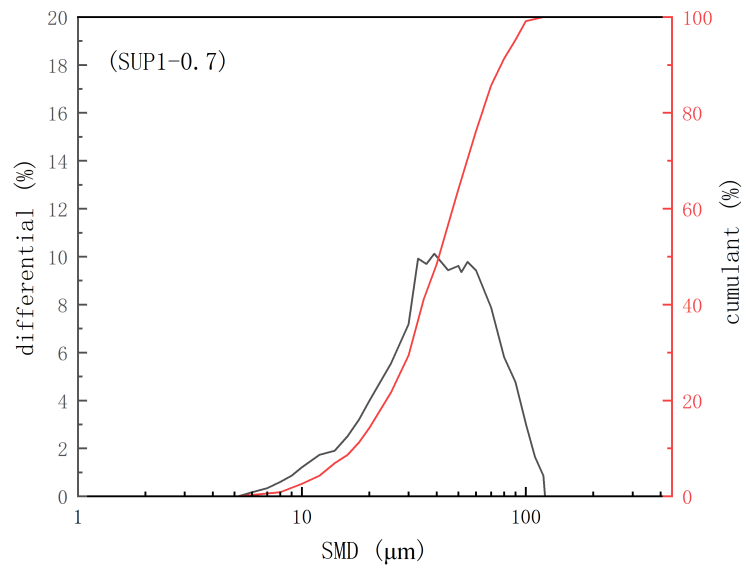

(h)

FIG. 4: Droplet size distribution under different conditions: (a) SUB1-0.7, (b) SUB2-0.4, (c) SUB2-0.4L, (d) SUB2-0.4S, (e) SUB2-0.5, (f) SUB2-0.7, (g) SUB2-0.7X, (h) SUP1-0.7

conditions are grouped according to different factors. The SMD was used as a criterion for evaluating the atomization performance and the relative size range for evaluating the degree of dispersion of the spray. A preliminary analysis of Table 3 reveals that the orifice arrangement and the order of the flow have little influence on the SMD and the relative size range of the droplets. Therefore, when plotting, the orifice diameter and momentum flux ratio were analyzed as the main influencing factors. Figure 5 presents the trend in the SMD and the relative size range of the spray with variation of the orifice diameter and the momentum flux ratio under different operating conditions.

\subsubsection{Injection Pressure Drop}

To study the influence of the injection pressure drop on the droplet size, SUB1-0.7 and SUB2-0.7 were analyzed. As can be seen from Fig. 4(a) and Fig. 4(b), the differential distribution curve of the droplet is wider at the injection pressure drop of $1 \mathrm{MPa}$, and the droplet size is larger

Volume 30, Issue 7, 2020 


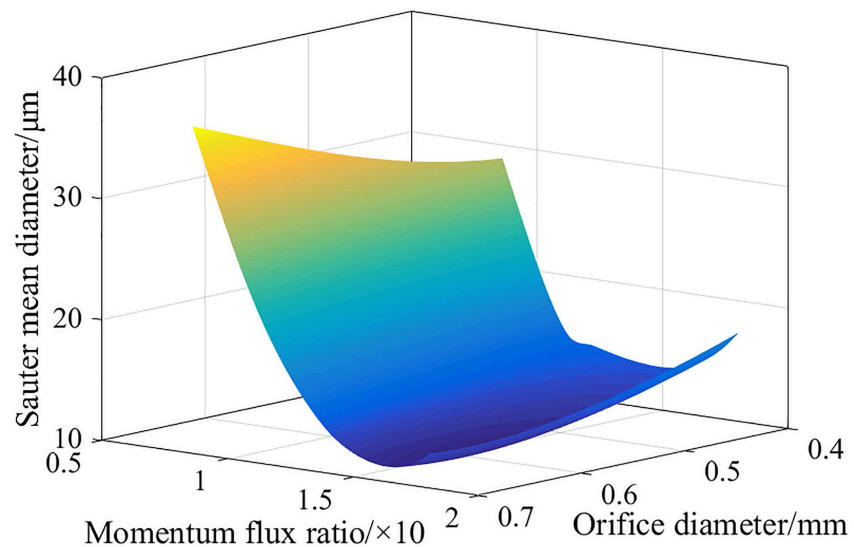

(a)

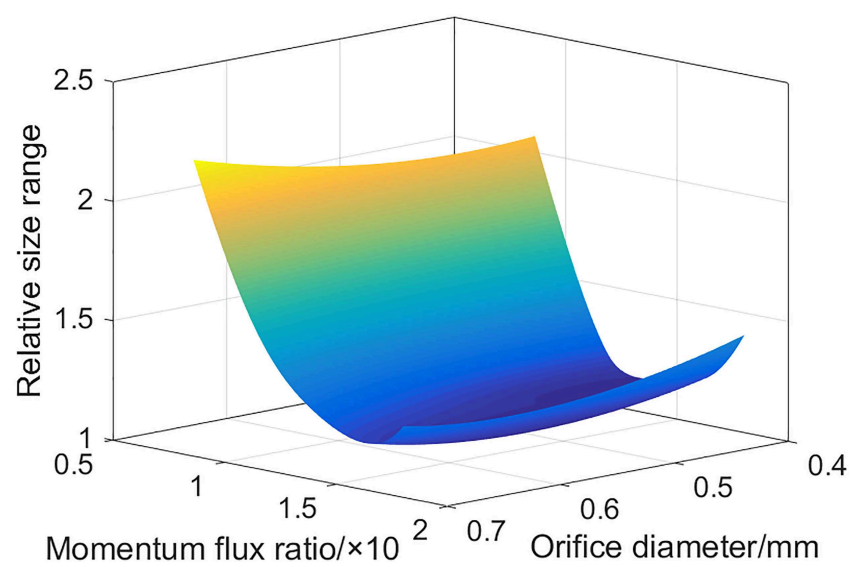

(b)

FIG. 5: Droplet size with varying parameters: (a) SMD; (b) Relative size range

at the peak position, indicating that the atomized droplet is large and non-uniform, with poor atomization effect. When the pressure increases to $2 \mathrm{MPa}$, the peak value moves forward and the large droplet disappears. At this time, the small particle droplet dominates and the atomization effect is significantly improved. The main reason is that as the pressure drop increases, the speed of the kerosene exiting the jet increases, which strengthens the air-liquid interaction and is beneficial to the droplets overcoming the surface viscosity force and enhancing the shear force. This improves the atomization effect and the atomization uniformity. It can also be seen from the test results that the SMD and relative size range of the droplets both decrease with increasing injection pressure drop.

\subsubsection{Orifice Diameter and Momentum Flux Ratio}

When analyzing the influence of the orifice diameter on the atomization characteristics, since it is difficult to control other variables to a fixed value, it is necessary to comprehensively analyze the multiple factors involved. Figure 5 presents the trend in the atomization characteristics with 
variation of the orifice diameter and the momentum flux ratio. It can be seen that the SMD and the relative size range of the droplets decrease as the momentum flux ratio increases but increases with the orifice diameter. When the momentum flux ratio increases, the growth trend of the SMD gradually flattens, and the influence of the momentum flux ratio on the atomization performance is much greater than that of the orifice diameter. The main reason for this is that the flow rate of the jet decreases with the orifice diameter, and the concentration of the atomized droplet group decreases, which increases the interaction between the gas and liquid. Therefore, the droplets are more likely to be broken, and the SMD of the droplets is smaller. When the momentum flux ratio is increased, the degree of surface breakage of the droplets is increased, which leads to a better atomization effect.

\subsubsection{Orifice Arrangement}

By studying SUB2-0.4L and SUB2-0.4S, the influence of the orifice arrangement on the atomization characteristics can be analyzed. It can be seen from Fig. 4(c) and Fig. 4(d) that the differential distribution curve of the design with multiple orifices aligned in the direction of the central flow is narrower, and the droplet size at the peak position is smaller. Combined with Table 3, it can be seen that there is no significant difference in the SMD of the two types, but their relative size ranges are significantly different. The design with multiple orifices aligned in the direction of the central flow has better atomization uniformity than the design arranged spanwise. In principle, although the wider spanwise atomization is beneficial in that it can make full use of the shear effect of the crossflow field, the influence of the wall boundary layer on mixing must also be considered, as it will result in uneven droplet size.

\subsubsection{Number of Orifices}

According to the results from different injection panels, the flow rate of an injector with an aperture of $0.7 \mathrm{~mm}$ is similar to that of an injector with three apertures of $0.4 \mathrm{~mm}$. Therefore, panels SUB2-0.4L and SUB2-0.7 were selected to study the influence of the number of orifices on the atomization characteristics. Comparing Fig. 4(c) and Fig. 4(f), it can be seen that compared with multiple orifice injection, the differential curve of single orifice injection is slightly narrower and the peak value is higher, indicating that the number of large droplets atomized by single orifice injection is relatively more. Therefore, the SMD of a single orifice is slightly larger, and its atomization uniformity is slightly better. Compared with single orifice injection, the flow field downstream from multiple orifice injection is quite different from the flow field upstream. The crossflow velocity before the upstream jet is larger, but after an oblique shock wave, the flow field before the downstream jet is mixed with a large number of droplets. As a result, the flow velocity before the downstream jet decreases, and the liquid-to-gas momentum ratio of the downstream jet decreases. Therefore, the atomization performance of multiple orifices is slightly worse than that of a single orifice.

\subsubsection{Crossflow Mach Number}

The influence of the crossflow Mach number on the atomization characteristics was analyzed and compared between SUB1-0.7 and SUB2-0.7. It can be seen that the larger the Mach number, the smaller the size of the atomized droplets and the better the droplet uniformity. Analyzing Fig. 4(a) and Fig. 4(h), under the condition of subsonic crossflow, the droplet size distribution is

Volume 30, Issue 7, 2020 
wide, and the frequency of large droplets is the highest. When the crossflow becomes supersonic, the peak position of the differential distribution moves forward, and the differential of the peak position drops to $10 \%$, indicating that the droplets atomized at this time are more uniform. This is because the larger the Mach number, the greater the shearing effect relative to the kerosene jet and the greater the dynamic pressure. Increasing the crossflow pressure increases the degree of surface breakage, which greatly improves the atomization performance.

According to comprehensive analysis of eight groups of data, the size of the atomized droplets increases with increasing orifice diameter, injection pressure drop, momentum flux ratio, and crossflow Mach number. The injection pressure drop and the momentum flux ratio have the greatest influence on the droplet size. In terms of atomization uniformity, the most uniform distribution results from a multiple-orifice structure arranged along the center line, indicating that the orifice arrangement has a significant influence on the atomization uniformity. When designing the injector, the influences of the orifice diameter, pressure drop, etc., on the atomization performance should be considered together to select the best conditions for atomization.

\subsection{Analysis of Penetration Height}

The fuel penetration height generally refers to the height to which the fuel penetrates into the crossflow. It is defined as the vertical distance between the outermost contour of the spray at the jet center section and the bottom surface. The penetration height of the jet reflects the degree of mixing of the fuel and the main stream. The larger the penetration height, the deeper the fuel jet penetrates into the main stream, indicating that the atomization effect is better (Liu et al., 2008).

In this paper, the schlieren method and high-speed photography were used to measure the fuel penetration height, and superimposed records were made on the entire flow field to obtain the trajectory and distribution of atomized kerosene in the flow field. Using image processing technology, kerosene penetration height curves were extracted, and the data were then fitted using a least-squares method to obtain an empirical formula for the penetration height.

\subsubsection{Penetration Height Measurement Results}

The conditions selected for the measurement of the penetration height were consistent with those for the measurement of the atomization characteristics. During the test, real-time measurements of the total pressure, static pressure, and injection pressure drop of fuel were collected. Penetration photographs under eight conditions were obtained, including two schlieren conditions and six high-speed photography conditions. Figure 6 presents a schlieren photograph from condition SUB2-0.5. Figure 7 presents a high-speed photograph from condition SUP2-0.7.

It can be seen from Figs. 6 and 7 that there is a large amount of kerosene attached to the glass at the exit end of the optical observation chamber in the subsonic crossflow, whereas there is no attached kerosene in the supersonic crossflow, and the flow field is relatively stable. In the subsonic crossflow, a square-to-round transfer segment and movable tail cone were assembled at the exit of the optical observation chamber, and it is speculated to have resulted in a decrease in the exit area and accumulation of kerosene. The kerosene penetration height can be clearly observed in each image, and the accumulation of kerosene does not affect its measurement. The pressure, pressure drop, momentum flux ratio, and other parameters for each operating condition are presented in Table 4.

By examining the parameter settings of each operating condition in Table 4, the influences of the injection pressure drop, orifice diameter, and momentum flux ratio on the penetration height 


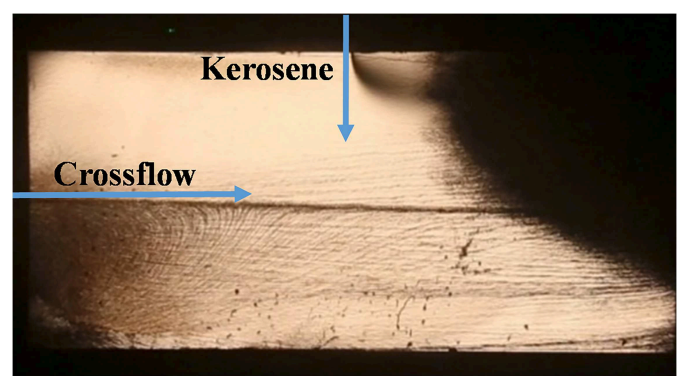

FIG. 6: Schlieren photograph $(\mathrm{Ma}=0.57)$

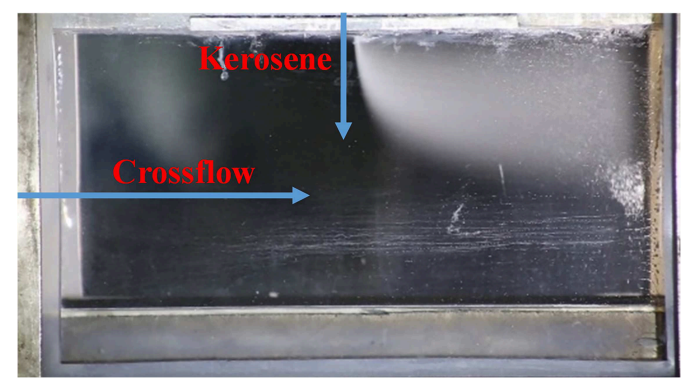

FIG. 7: High-speed photograph $(\mathrm{Ma}=2)$

TABLE 4: Test parameters under different operating conditions

\begin{tabular}{ccccccc}
\hline & Conditions & Injection panel & $\boldsymbol{P}_{\mathbf{0}}(\mathbf{M P a})$ & $\boldsymbol{P}(\mathbf{M P a})$ & $\boldsymbol{\Delta P}(\mathbf{M P a})$ & $\boldsymbol{q}$ \\
\hline 1 & SUB1-0.7 & 1 & 1.86 & 0.74 & 1.21 & 9.11 \\
2 & SUB2-0.4 & 3 & 1.67 & 1.39 & 2 & 8 \\
3 & SUB1-0.7 & 1 & 1.89 & 1.23 & 1.09 & 4.89 \\
4 & SUB2-0.4 & 3 & 1.87 & 1.35 & 2 & 9.33 \\
5 & SUB2-0.5 & 2 & 1.91 & 1.19 & 1.9 & 8.89 \\
6 & SUB2-0.7 & 1 & 2.24 & 1.05 & 2.09 & 11.11 \\
7 & SUB1-0.7 & 1 & 1.84 & 0.75 & 0.97 & 7.22 \\
8 & SUP2-0.7 & 1 & 2.06 & 0.84 & 1.77 & 1.05 \\
\hline
\end{tabular}

1 and 2 were measured by schlieren, 3-8 were measured by high-speed photography.

can be analyzed. When measuring the influence of one of the variables, it is difficult to control other factors. Therefore, when analyzing the effects of these variables on the penetration height, multiple factors need to be combined.

\subsubsection{Image Processing and Penetration Height Fitting}

Our analysis used Matlab to process the penetration height images. A threshold gray value of 100 was selected to define the boundary of the penetration curve of the kerosene. The main process was as follows: (1) Dimension calibration: the pixel coordinate system in the image is calibrated to the real-world coordinate system. (2) The brightness and contrast of the image are 
adjusted to enhance the difference between the background color and the atomization area. (3) The atomization image is converted from a color to a grayscale image. (4) The image is cropped to the atomized region to avoid the influence of other regions on data extraction. (5) According to the definition of the kerosene penetration height, an appropriate threshold value is selected for binarization. (6) The boundary of the atomization area is extracted from the binarized image. (7) Data representing the boundary are extracted and processed to remove isolated points. (8) An empirical formula for the penetration height is obtained using a least-squares method to fit the data. Taking SUB2-0.7 as an example, the images obtained in this process are presented in Fig. 8.

The penetration curves extracted under different operating conditions were compared and analyzed, as presented in Fig. 9. This graph presents penetration curves obtained by high-speed photography, indicating the trend in the penetration height with axial distance under different operating conditions. It can be seen that the trend in the penetration height was consistent under all operating conditions. The penetration height of SUB2-0.4 was the largest, which suggests that the smaller the orifice diameter and the greater the pressure drop, the larger the penetration height. These two factors are both related to the momentum flux ratio, indicating that the momentum flux ratio has the greatest influence on the penetration. By analyzing the penetration height of SUB2-0.7 and SUP2-0.7, it can be seen that the penetration height of supersonic inflow is larger, which is consistent with the conclusions of other studies (Portz and Segal, 2006). When the crossflow Mach number increases, the penetration height increases.

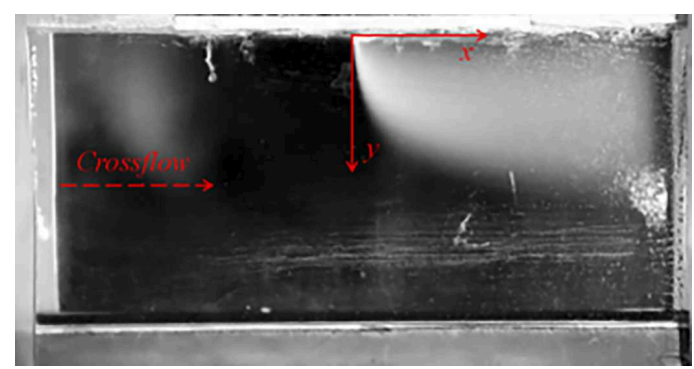

(a)

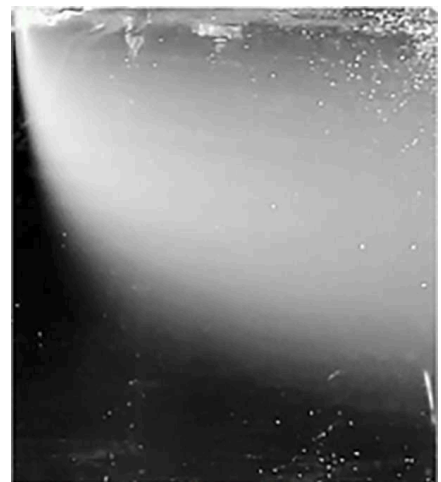

(c)

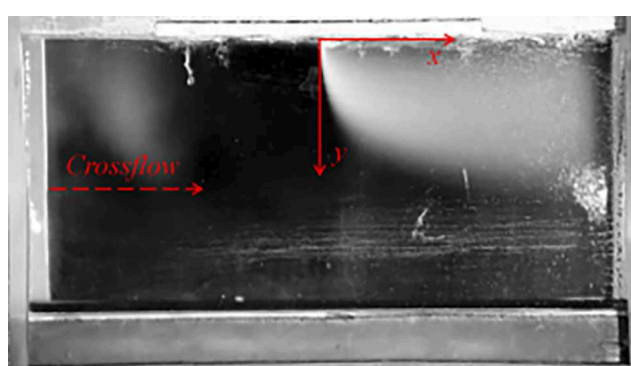

(b)

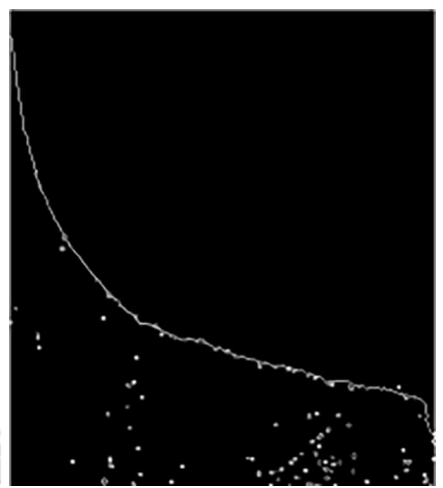

(e)

FIG. 8: Penetration height image processing process for a kerosene jet in a crossflow: (a) intensity control; (b) grayscale image; (c) cropped atomization area; (d) binarized image; (e) boundary extraction 


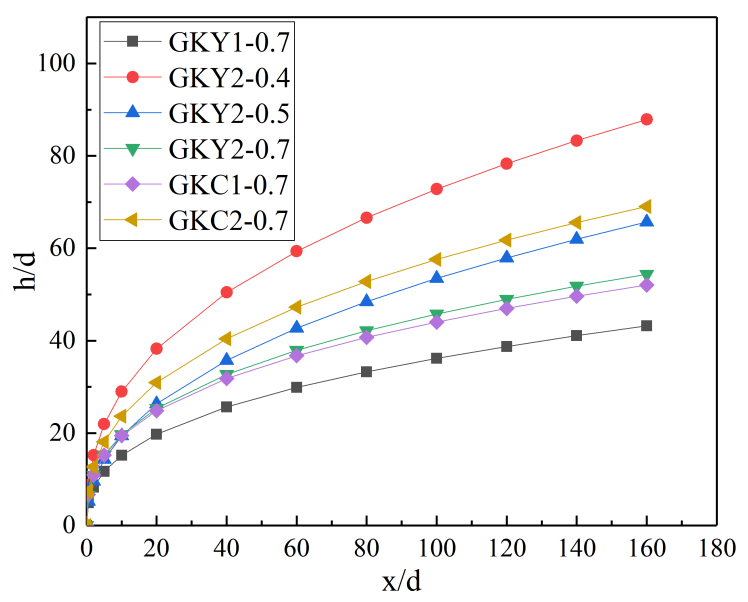

FIG. 9: Fitting curves of penetration height under different conditions

In general, the penetration height of the spray increases with increasing momentum flux ratio. The main reason for this is that the dynamic pressure of the crossflow causes the jet to flatten and bend in the direction of the crossflow, and the dynamic pressure of the kerosene jet provides penetrating force to the jet. Therefore, the greater the dynamic pressure of the kerosene jet, the greater the penetration height. Furthermore, with increasing crossflow Mach number and axial distance, the penetration height also gradually increases. The influence of the momentum flux ratio and the axial distance is more significant. When the penetration height of the spray is relatively small, the distance between the lower edge of the spray and the wall surface is very small, and adherent flow occurs. Some droplets collide with the wall surface, which is not conducive to atomization and mixing. Therefore, the occurrence of adherent flow should be avoided as far as possible.

After comprehensive analysis of the impact of momentum flux ratio on droplet size and penetration height, it was found that the increase of momentum flux ratio will improve the atomization performance and penetration height of the jet. The improvement of atomization performance makes the droplets more likely to be broken, thereby increasing the specific surface area of the droplet. And, increasing the penetration height will make the jet closer to the center of the mainstream. Large specific surface area and penetration height will effectively increase the degree of mixing of the jet and crossflow, which will improve the combustion efficiency of fuel to a certain extent.

Figure 10 presents penetration height fitting curves obtained from high-speed photography and the schlieren method under the same operating conditions (SUB2-0.5). It can be seen from the figure that the measurement results in the near-field area are relatively similar, whereas the results in the far-field area with high-speed photography are larger. However, overall, the measured penetration heights are similar. The penetration height fitting formulas are different for the different measurement methods.

It can be seen from Table 4 and Fig. 9 that the momentum flux ratio and axial distance have the largest influence on penetration, which is consistent with the results of previous studies (Liu et al., 2008; Lin and Kennedy, 2002; Sun et al., 2013; Wang et al., 2015a; Li et al., 2016). The empirical formula for penetration height used by various scholars is mainly a power function. The empirical formula for penetration height used for fitting in this paper is presented in Eq. (2):

Volume 30, Issue 7, 2020 


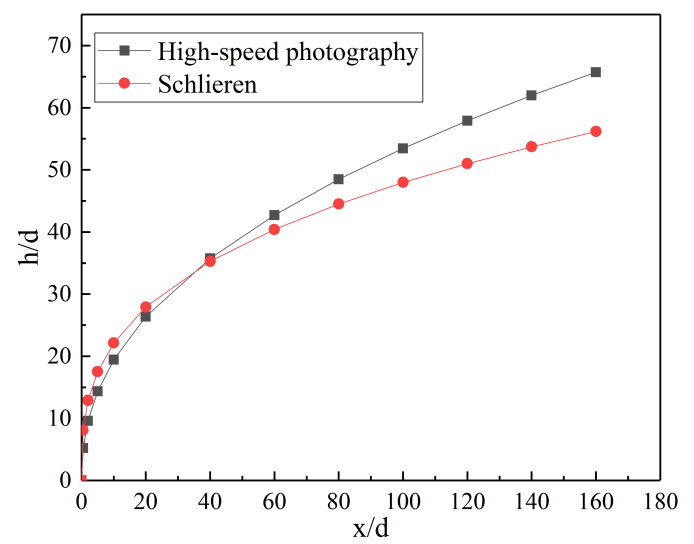

FIG. 10: Comparison of penetration heights between the two measurement methods

$$
\frac{h}{d}=a \cdot q^{b} \cdot\left(\frac{x}{d}\right)^{c}
$$

where $h$ is penetration height, $d$ is orifice diameter, $q$ is momentum flux ratio, $x$ is axial distance, and $a, b$, and $c$ are constants.

In the process of formula fitting, the momentum flux ratio term and the constant term were considered to be constants to reduce the loss caused by the fitting, and then the momentum flux ratio under each operating condition was substituted into the formula for quadratic fitting. The first fitting results are presented in Table 5. The fitting accuracy of the empirical formulas presented in Table 5 is about $98 \%$, and the fitting effect is good. Because of the differences in the measuring method and crossflow Mach number, the penetration height formulas are different. Therefore, in this study, only the penetration curves in subsonic crossflows obtained by highspeed photography were used for fitting. When the crossflow Mach number is 0.6, the empirical formula for the penetration height is as presented in Eq. (3):

TABLE 5: The initial fitting formulas for penetration height under each operating condition

\section{Conditions}

Schlieren SUB2-0.4

Schlieren SUB2-0.5

High-speed photography SUB1-0.7

High-speed photography SUB2-0.4

High-speed photography SUB2-0.5

High-speed photography SUB2-0.7

High-speed photography SUP1-0.7

High-speed photography SUP2-0.7

\section{Penetration height}

empirical formula

$$
\begin{gathered}
h / d=9.071 \cdot(x / d)^{0.345} \\
h / d=10.21 \cdot(x / d)^{0.336} \\
h / d=6.407 \cdot(x / d)^{0.376} \\
h / d=11.54 \cdot(x / d)^{0.4} \\
h / d=7.08 \cdot(x / d)^{0.439} \\
h / d=8.444 \cdot(x / d)^{0.367} \\
h / d=8.59 \cdot(x / d)^{0.355} \\
h / d=9.732 \cdot(x / d)^{0.386}
\end{gathered}
$$




$$
\frac{h}{d}=3 \times 365 \cdot q^{0.429}\left(\frac{x}{d}\right)^{0.393}
$$

This equation shows the trend in the penetration height with momentum flux ratio and axial distance. When the other conditions are the same, the larger the momentum flux ratio, the larger the penetration height. The fitting error for Eq. (3) is large, mainly due to the use of relatively few conditions, resulting in too few data points.

Table 6 lists some empirical formulas for penetration height fitted by previous researchers. The empirical formula for penetration height fitted in this paper is compared with those fitted by previous researchers. The exponent of the momentum flux ratio is 0.429 , which is similar to the values in the literature. It was found that the exponent of the momentum flux ratio is very close to that of the axial distance, indicating that the momentum flux ratio and the axial distance have a close influence on the penetration height. The constant terms in each of the other studies have certain differences related to the test method, test environment, crossflow Mach number (Lin et al., 2004), and other factors. Considering an orifice diameter of $0.5 \mathrm{~mm}$ and a momentum flux ratio of 10, the penetration height fitting curves obtained in this paper were compared with some penetration height fitting curves in Table 6, and the results are presented in Fig. 11.

It can be seen that the penetration heights obtained by different researchers in the near-field area are almost the same, whereas those in the far-field area exhibit significant differences. The penetration height obtained in this paper is larger than the values found in other studies, and the measurement results from PDPA are higher than those from the schlieren method and PLIF. These differences are probably related to the differences in test principles, the definition of the boundary of the penetration height, and the test conditions.

The PDPA method can obtain the distribution of the spray through laser scanning of the entire flow field and has higher measurement accuracy. The schlieren method uses the density gradient of the spray field to generate a change in light intensity and then to judge the distribution of the spray. For the small particles around the spray, the density gradient is small, and the light intensity is weak, which is difficult to capture. The PLIF method uses a laser to irradiate fluorescent substances and to obtain the distribution of the spray in the flow field. Where the concentration of the spray is high, the fluorescence signal is strong, and where the concentration is low, the fluorescence signal is weak. High-speed photography uses optical imaging to sample high-speed objects quickly and repeatedly in a short time to obtain a clear image. However, the electrical signal is weak, and the distribution of the spray is not obvious in the areas with a small concentration of spray. Different researchers have different definitions of penetration height. Lin and Kennedy (2002) define the boundary of penetration height as the location where the measured liquid volume flux is $0.01 \mathrm{cc} / \mathrm{s} / \mathrm{cm}^{2}$ at $y=0$. When processing the penetration height curves, Liu et al. (2008) define the penetration height of the jet as the vertical distance from the outermost contour of the liquid mist at the center section of the jet to the bottom surface. Wang et al. (2015a) set the background gray value to 0 , leaving the gray value of the spray area unchanged, and defined the boundary curve with a gray value of 125 as the outer edge of the jet. In this paper, when processing high-speed photographic images, a curve with a gray value of 100 was selected as the boundary of the kerosene penetration.

Based on the test principles and the definition of the penetration height boundary, the results obtained in this paper were analyzed. In the near-field area, the jet is not completely atomized, and the spray concentration is large and relatively concentrated. Different measurement methods have little influence on the penetration height measurement results, so the penetration height

Volume 30, Issue 7, 2020 


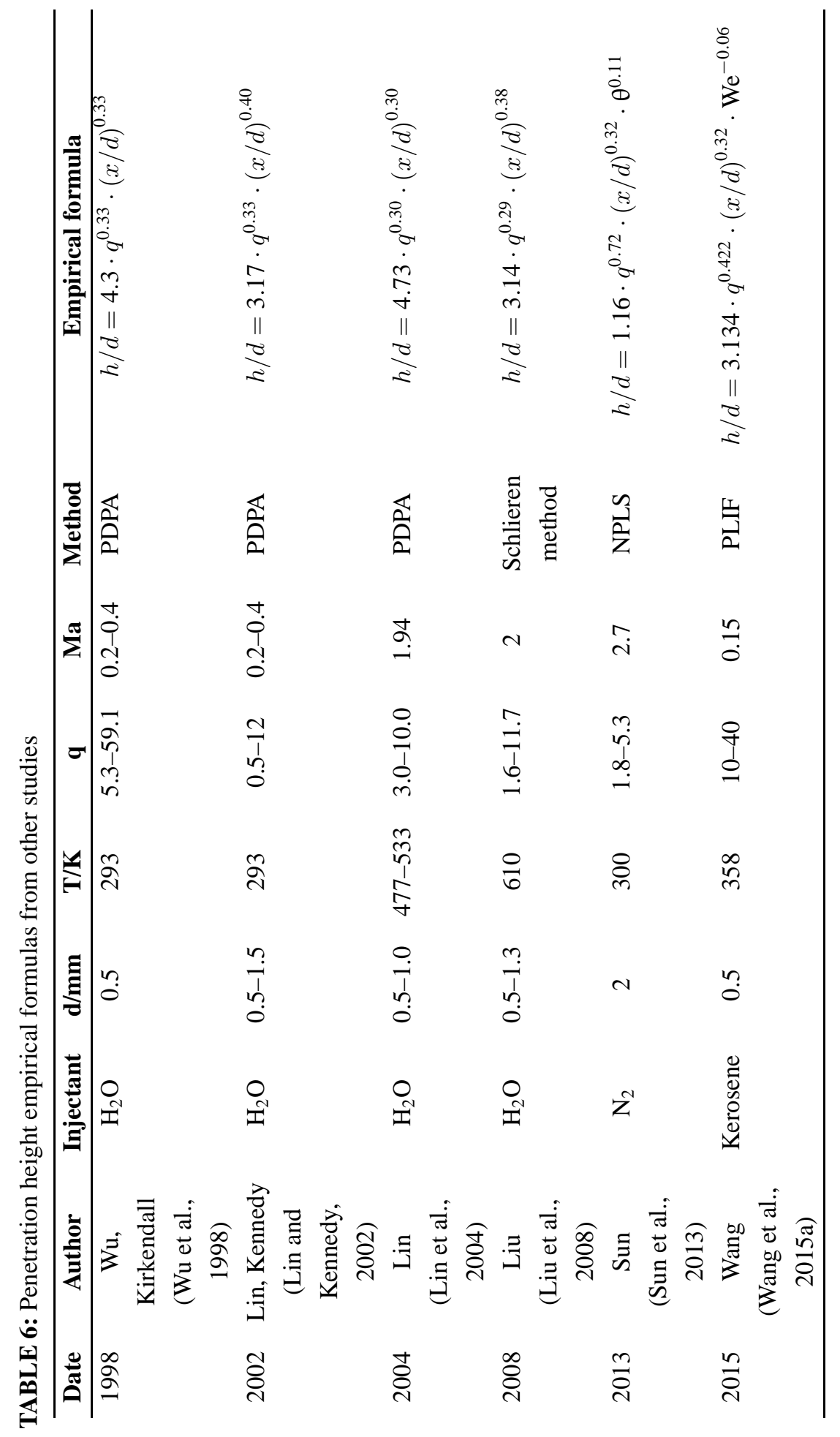




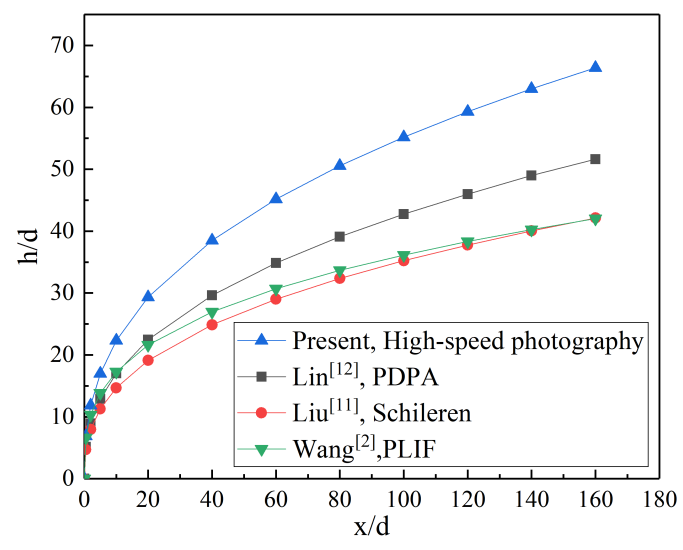

FIG. 11: Comparison of penetration height curves

obtained for this region in different studies is relatively consistent. In the far-field area, the atomization mixing process is basically completed, and the outermost concentration of the spray is very small, which is difficult to capture using the schlieren method, PLIF, or high-speed photography. The measurement result in this area is therefore likely to be lower than that measured using PDPA. However, the penetration height obtained in this paper is higher than the PDPA measurement, mainly due to the different definitions of the penetration height boundary. Compared with the value used by Wang et al. (2015a), the gray value used to define the outermost edge of the spray in this study is small, which means that the concentration of spray taken as the outermost limit will be smaller, and the penetration height will therefore be larger.

As noted, the empirical formulas for penetration height obtained by different researchers are not the same. This is mainly for the following reasons. Different test methods have different measurement accuracies, and PDPA has high measurement accuracy. Furthermore, different researchers use different definitions of the jet boundary, and when extracting the boundary of the penetration height, the gray threshold is selected somewhat arbitrarily. In addition, differences in the test medium, test conditions, and test environment can cause differences in the jet penetration height.

\section{CONCLUSION}

In this paper, kerosene was used as the research object, and the droplet size and penetration height of kerosene in crossflows were studied. The SMD and relative size range of the atomized kerosene were measured using PDA. The penetration height of the kerosene jet was measured by the schlieren method and high-speed photography. The main conclusions are as follows:

(1) There is a strong interaction between the liquid jet and the crossflow. The larger the injection pressure drop and the crossflow Mach number, the stronger the gas-liquid interaction and the better the atomization performance. The smaller the orifice diameter, the smaller the SMD of the atomized droplets. Compared with a single orifice, a multiple-orifice structure distributed along the direction of the center line of the combustion chamber is more favorable for the uniformity of the atomized droplets.

(2) The penetration height is positively correlated with the momentum flux ratio, orifice diameter, and crossflow Mach number and is most affected by the momentum flux ratio. To

Volume 30, Issue 7, 2020 
improve the atomization and mixing of the fuel, the jet penetration height should be adjusted to increase the contact area between the jet and the crossflow, and adherent flow should be avoided.

(3) The penetration height of subsonic and supersonic crossflows was measured using the schlieren method and high-speed photography. The empirical formula for the penetration height in a subsonic crossflow was found to be $h / d=3.365 \cdot q^{0.429}(x / d)^{0.393}$. Compared with the formulas obtained by other researchers, it was found that the overall trend in the penetration height curve is consistent. However, due to the influence of the measurement methods, definition of the penetration height boundary, test medium, test conditions, and image processing methods, the empirical formulas for the penetration height obtained by different researchers have certain differences.

\section{ACKNOWLEDGMENT}

This study is supported by the National Natural Science Foundation of China (No. 51676165).

\section{REFERENCES}

Allan, S. and Joseph, S., Breakup of Liquid Sheets and Jets in a Supersonic Gas Stream, AIAA J., vol. 9, no. 4, pp. 666-673, 1971. DOI: 10.2514/6.1970-89

Ebrahimi, H., Numerical Investigation of Jet Interaction in a Supersonic Freestream, J. Spacecraft Rockets., vol. 45, no. 1, pp. 95-103, 2013. DOI: 10.2514/1.29847

Gad, H.M., Ibrahim, I.A., and Abdel-baky, M.E., Experimental Study of Diesel Fuel Atomization Performance of Air Blast Atomizer, Exp. Therm. Fluid Sci., vol. 99, pp. 211-218, 2018. DOI: 10.1016/j.expthermflusci.2018.07.006

Huang, W., Transverse Jet in Supersonic Crossflow, Aerospace Sci. Technol., vol. 50, no. 3, pp. 183-195, 2016. DOI: 10.1016/j.ast.2016.01.001

Joshi, P.B. and Schetz, J.A., Effect of Injector Shape on Penetration and Spread of Liquid Jets, AIAA J., vol. 13, no. 9, pp. 1137-1138, 2015. DOI: 10.2514/3.60518

Jinbum, H. and Seungsoo, L., Numerical Study on Lateral Jet Interaction in Supersonic Crossflows, Aerospace Sci. Technol., vol. 80, pp. 315-328, 2018. DOI: 10.1016/j.ast.2018.07.022

Kolpin, M.A., Horn, K.P., and Reichenbach, R.E., Study of Penetration of a Liquid Injectant into a Supersonic Flow, AIAA J., vol. 6, no. 5, pp. 853-858, 1968. DOI: 10.2514/3.4609

Kush, E.A. Jr. and Schetz, J.A., Liquid Jet Injection into a Supersonic Flow, AIAA J., vol. 11, no. 9, pp. 1223-1224, 1973. DOI: 10.2514/3.50567

Krishnan, M., The Interaction of Jets with Crossflow, Annu. Rev. Fluid Mech., vol. 45, no. 3, pp. 379-407, 2013. DOI: 10.1146/annurev-fluid-120710-101115

Li, Y., Wei, H., Hao, L., et al., Numerical Investigation and Optimization on Mixing Enhancement Factors in Supersonic Jet-to-Crossflow Flow Fields, Acta Astronautica, vol. 127, no. 10, pp. 321-325, 2016. DOI: $10.1016 /$ j.actaastro.2016.06.011

Lin, K.C. and Kennedy, P., Spray Penetration Heights of Angle-Injected Aerated-Liquid Jets in Supersonic Crossflows, Aerospace Sciences Meeting \& Exhibit, Reno, Nevada, January 10-13, 2000.

Lin, K.C. and Kennedy, P.J., Penetration Heights of Liquid Jets in High-Speed Crossflows, 40th AIAA Aerospace Sciences Meeting \& Exhibit, 2002.

Lin, K.C., Kennedy, P., and Jackson, T., Structures of Water Jets in a Mach 1.94 Supersonic Crossflow, 42nd AIAA Aerospace Sciences Meeting and Exhibit, pp. 12096-12115, 2004. 
Liu, J., Wang, L., Zhang, J., et al., Experimental and Numerical Simulation of Atomization of Liquid Jet in Supersonic Crossflow, J. Aerospace Power, vol. 23, no. 4, pp. 724-729, 2008. (in Chinese)

Miller, B.D., Digital Holographic Diagnostics of Aerated Liquid Jets in a Subsonic Crossflow, MSME, Oklahoma State University, 2006.

Morad, M.R. and Khosrobeygi, H., Penetration of Elliptical Liquid Jets in Low-Speed Crossflow, J. Fluids Eng., vol. 141, no. 1, pp. 1-7, 2019. DOI: 10.1115/1.4040373

Portz, R. and Segal, C., Penetration of Gaseous Jets in Supersonic Flows, AIAA J., vol. 44, no. 10, pp. 2426-2429, 2006. DOI: 10.2514/1.23541

Stenzler, J.N., Lee, J.G., Santavicca, D.A., et al., Penetration of Liquid Jets in a Crossflow, Atomization Sprays, vol. 16, no. 8, pp. 887-906, 2006. DOI: 10.1615/AtomizSpr.v16.i8.30

Sun, M.B., Gong, C., Zhang, S.P., et al., Spark Ignition Process in a Scramjet Combustor Fueled by Hydrogen and Equipped with Multi-Cavities at Mach 4 Flight Condition, Exp. Therm. Fluid Sci., vol. 43, pp. 90-96, 2012. DOI: 10.1016/j.expthermflusci.2012.03.028

Sun, M.B., Zhang, S.P., Zhao, Y.H., et al., Experimental Investigation on Transverse Jet Penetration into a Supersonic Turbulent Crossflow, Sci. China Technol. Sci., vol. 56, no. 8, pp. 1442-1447, 2013. DOI: $10.1007 / \mathrm{s} 11431-013-5265-7$

Tambe, S.B., Jeng, S.-M., and Mongia, H., Liquid Jets in Subsonic Crossflow, 43nd AIAA Aerospace Sciences Meeting and Exhibit, Reno, Nevada, January 10-13, 2005.

Wang, H.B., Wang, Z.G., Sun, M.B., et al., Combustion Modes of Hydrogen Jet Combustion in a CavityBased Supersonic Combustor, SciVerse ScienceDirect, vol. 38, no. 27, pp. 12078-12089, 2013. DOI: 10.1016/j.ijhydene.2013.06.132

Wang, Z.G., Wu, L., Li, Q., et al., Experimental Investigation on Structures and Velocity of Liquid Jets in a Supersonic Crossflow, Appl. Phys. Lett., vol. 105, no. 13, pp. 134-102, 2014. DOI: 10.1063/1.4893008

Wang, Y.S., Lin, Y.Z., Li, L., et al., Research on Penetration of Aviation Kerosene Injected into Crossflows based on PLIF Technique, J. Propuls. Technol., vol. 36, no. 09, pp. 1395-1402, 2015a. (in Chinese)

Wang, Z.G., Sun, M.B., Wang, H.B., et al., Mixing-Related Low Frequency Oscillation of Combustion in an Ethylene-Fueled Supersonic Combustor, Proc. Combust. Inst., vol. 35, no. 2, pp. 2137-2144, 2015 b. DOI: $10.1016 /$ j.proci.2014.09.005

Wang, H.B., Wang, Z.G., Sun, M.B., et al., Large Eddy Simulation of a Hydrogen-Fueled Scramjet Combustor with Dual Cavity, Acta Astronautica, vol. 108, pp. 119-128, 2015c. DOI: 10.1016/j.actaastro.2014.12.008

Wu, P.K., Kirkendall, K.A., Fuller, R.P., et al., Spray Structures of Liquid Jets Atomized in Subsonic Crossflows, J. Propuls. Power, vol. 14, no. 2, pp. 173-182, 1998. DOI: 10.2514/2.5283

Yu, G., Li, J.G., Zhao, J.R., et al., An Experimental Study of Kerosene Combustion in a Supersonic Model Combustor Using Effervescent Atomization, Symposium Combust., vol. 30, no. 2, pp. 2859-2866, 2004. DOI: $10.1016 /$ j.proci.2004.07.050

Volume 30, Issue 7, 2020 